\title{
On the Role of Phraseological Units in Teaching English as a Foreign Language to Adult Learners
}

\author{
Minoo Khamesian \\ Sanaati Noushirvani University
}

\begin{abstract}
One of the challenges of learning English for Iranian learners is "nativelike" production of speech rarely achieved by even the most advanced learners. Unfortunately, it is common belief among Iranian English learners that knowledge of individual lexical items is the key to communicative competence. But alas! The outcome has shown this is counterproductive. As an anglicist teaching ESP in general and EAP in particular in my country, I feel responsible for shedding light on this issue inasmuch as I experience the lapse in my everyday professional work. It should be noted that in this Global Village, in which English is considered the Lingua Franca of science and technology, focusing on phraseological units as a sub-branch of lexical proficiency seems to be of paramount importance to avoid misunderstanding and miscommunication. The present article makes an effort to highlight the role of contextual usages of these units in TEFL to help the learners reach the desired native-like production of English speech.
\end{abstract}

Key words: phraseology, idiomaticity, collocational proficiency, nativelikeness.

\section{Introduction}

Language and culture are, needless to say, intimately linked. Different schools of thought, for instance, Prague school of linguistics, or FirthianHallidayan functional-systemic British Contextualism, view language as a social phenomenon primarily, as it is intertwined with culture both naturally and inextricably. Such approaches, in addition to those socio-culturally and contextually oriented, tend to view language as embedded in culture to the 
extent that linguistic proficiency can only be reached providing that the cultural context embracing it is properly referred to. The functions of phraseological units from many researchers' works can be summarized as first and foremost indicating how these units contribute to the production of creative language and fluency, as well as help avoid misunderstanding, improving the users' native-likeness in communication.

When it comes to producing a text or a piece of speech, according to Sinclair (2004), seldom do we have the chance of selecting a single word freely, but there is a phraseological tendency by means of which meaning is built. This phraseological nature of language is further explained by Bolinger (1976:1) as, "language does not expect us to build everything starting with lumber, nails, and blueprint, and rather it provides us with an incredibly large number of prefabs." Sinclair (2004b:19-20) also argues that words do not "constitute independent selections". Rather, co-selection is the norm, "the choice of one word conditions the choice of the next, and of the next again". Otherwise stated, this sharing entails that "[...] the meaning of words chosen together be different from their independent meanings", leading to a certain "delexicalization" of words, as a result. According to Gibbs (1993), it is essential to study idioms not only because they help us comprehend how people learn and communicate figurative language, but also because idiomaticity opens the door to some dramatic insights into how language and thought are interconnected.

\section{Phraseologies and Teaching Language to Non-Natives}

We should bear in mind that language tends not only to be controlled by grammatical rules and regulations, but by lexical and discursive co-selections as well. In this regard, the phraseologies of a given language (in our case the English language) can thus be taken as a means to differentiate native language from learner language. The latter has been termed differently, e.g. "informal, speech-like" (Granger \& Rayson, 1998:130), "bookish and pedantic" (Channell, 1994:21), "vague and stereotyped" and having "limited vocabulary" (Ringbom, 1998:49), or lacking idiomaticity (Lorenz, 1998:53), all of which imply that 
learner language contains its own style, which is generally referred to as "unnatural" or "non-native".

On the other hand, as Cowie (2005:12) puts, "Prefabricated expressions pervade all levels of linguistic organization - lexical, grammatical, pragmatic and affect all kinds of structures, from entire utterances to simple phrases [...], there are relatively few examples that are completely invariable or opaque." Thus, to select the most natural alternative from among a broad range of grammatically possible sentences in any given situation calls for something beyond knowledge of syntax. Being ubiquitous in the English language, and arguably, allocating a large part of the native's vocabulary to themselves, these prefabricated expressions require to be paid due attention while teaching the language to the non-native. The foreign language learner, not being familiar with them, would devise structures in the hope that native speakers would be unable to communicate without misunderstanding, but the result is likely to be highly contrived and unacceptable to native ears.

When it comes to cultural differences between languages, the interference of the native language of the learner makes the learning process even worse. Furthermore, according to Wray (2002:206), another problem the learner should challenge is having so many choices - paradigm - so a wrong selection would undoubtedly result in unnaturalness, and, as a result, correct use of words seems to be an essential counterpart of expressive and effective speech.

Wolter (2006) shows that the learner's mother tongue would provide a preset structure of concepts, and as a consequence of the dissimilarities between lexical sources, miscollocations might be inevitable. Learners make collocational errors mainly due to the fact that they rely on their L1 lexical knowledge. However, the acquisition of new combinations of words in L2 will lead to "conceptual modifications", as a result of which problems manifest. This is further elaborated by Danesi's conceptual fluency, which argues that "students 'speak' with the formal structures of the target language, but they 'think' in terms of their native conceptual system" (Danesi 1995). 


\section{Analysis}

What is adduced below is drawn from my English learners' speeches, who devised these usages naturally and spontaneously. It should be added that my learners of English generally have rather a good command of English and target IELTS or TOEFL to seek a post-degree or a job opportunity overseas.

In actual fact, my collection is noticeably overwhelming, but as it is impossible to include all, I decided to select some of those with the highest frequency of occurrence in every day communication. The native-like English equivalents are presented after each misused phrase. The collection, although small, hopefully will be enough to meet my claim in this study.

Empty your place.

It was a shame you weren't with us.

He is not in the garden.

His mind is somewhere else.

Your father will be killed.

Your goose is cooked.

Don't be tired.

(The word by word translation of how Iranians farewell at the end of a working day; see you.)

Any order?

(Again, the direct translation of How can I help you.)

He looked at me left left.

He looked at me angrily.

His hen has one leg.

He is headstrong.

His donkey has crossed the bridge.

He is out of the woods.

Her writing is lobster and frog.

His writing isn't legible.

Wants both God and date.

(Which surprisingly means Have your cake and eat it.) 
I should hasten to add that such violations tend to be a natural manifestation of the playful, creative energy. The oddness of expressions built by the learners, as obvious, is not associated with grammatical deficiency. They seem to occur due to the mental models of Farsi, the mother tongue. The interference of semantics and syntax of Farsi is obviously visible. Considering the nature of phraseology, i.e. the arbitrary co-selection of words to be combined, we can put it at an area between grammar and meaning.

Surprisingly enough, the learners are interested in using idiomatic structures, but rarely do they bother themselves to find out what the genuine equivalents are. Such pragmatic clusters, as I would like to call, are made up of a string of words, the meaning of which can rarely, if ever, be taken in literally. As Wray (2002:465) puts, “A sequence, continuous or discontinuous of words or other meaning elements, is, or appears to be prefabricated; that is stored and retrieved whole from the memory at the rime of use, rather than being subject to generation or analysis by the language grammar." Sinclair (2004), on the other hand, explains that when producing a text or speech, we are not entirely free to choose a single word inasmuch as there is a phraseological tendency according to which meanings can be created in terms of word combinations.

The cultural distance or so-called alienness of the utterances clearly shows that the learners do not share in the socio-cultural knowledge of native English speakers or common ways of how they speak. Following what Bakhtin (1981:346) puts concerning every discourse presupposing a special conception of the listener, of his perceptive background and the degree of his responsiveness, I would assert that the differences found from the two cultural contexts and in the two languages contribute to establishing distance towards the readership, ailing true understanding. It is also worth adding here that Bolinger (1976:1) elaborates on the phraseological nature of language stressing out that "language does not expect us to build everything starting with lumber, nails, and blueprint. Rather it provides us with an incredibly large number of prefabs."

Sadly enough, the majority of the poor phraseological performances were produced by advanced learners, which can strengthen the fact that they are deficient in collocational relationship between words in idiomatic expressions. 
For them, this tends to be initially regarded as compositional combinations of words not a phenomenon of co-selection.

What is worthy of note here is that contrary to some study results indicating that learners tend to use a limited number of collocations (those they are sure about) - Iranian learners create collocations in English unnervingly extravagantly, happily expecting their interlocutors to understand them.

As written time and again, phraseological cohesion tends to be more challenging than lexical cohesion due to its semantic structure, hence it will not be irrational to claim that the inherent feature of any unit of phraseology is the cohesion of the base form, including not only grammatical, lexical, and phonological but also stylistic aspects. Wolter (2006:746) puts that "the process of building syntagmatic connections between words in L2 appears to be considerably harder than the process for building paradigmatic connections." Therefore, it does not seem unreasonable to say that idiomatic competence is highly likely to develop after extensive exposure to the pragmatics of idiomaticity in the sociocultural contexts of a specific discourse community.

\section{Conclusion}

Undeniably, cross-cultural communication is essential in the world today, but sadly, it seems not to enjoy the attention it deserves among the teachers. English teachers in general and in Iran in particular, should be aware of the fact that our task is not merely teaching the language rules and the vocabulary, but also raise our learners' awareness of the important role the English culture plays in our ability of native-like production of speech.

It is also worth bearing in mind that we cannot expect our learners to communicate in English naturally if the vocabulary of English is taught as single items without collocational relationships in terms of idiomaticity. It is necessary for learners' attention to be diverted from single lexical items to habitual word combinations, whose meanings could be perceived through intralinguistic relations that exist between them. This does not necessarily overlook the fact that lexical items relate to concrete features of the real world but stresses out that the meaning would not solely be comprehensible in terms 
of the referential approach.

It is of paramount importance for us as English teachers to find out lexical restrictions in teaching idioms which due to their purely intralinguistic nature, cannot be accounted for by logical considerations. Also important for an efficient teacher is to be aware of the fact that for a native-like command of English in general, and idiomatic English in particular, words, word-groups and sentences must be shed light on within the lexical, grammatical and situational restrictions of the language.

\section{References:}

1. Bakhtin, M.M. (1981) The Dialogic Imagination. Austin, TX: University of Texas Press.

2. Bolinger, D. (1976) Meaning and Memory. // Forum Linguisticum, 1, 1-14.

3. Channell, J. (1994) Vague Language. Oxford: Open University Press.

4. Cowie, A. (ed.). (2005) Phraseology: Theory, Analysis, and Applications. New York: OUP.

5. Danesi, M. (1995) Learning and Teaching Languages: The role of "conceptual fluency." // International Journal of Applied Linguistics, 5(1), 3-20.

6. Firth, J.R. (1968a) A Synopsis of Linguistic Theory, 1930-1955 (Special volume of the Philological Society, Oxford, 1957, 1-31). // Selected papers of J.R. Firth 1952-1959. / Ed. by F.R. Palmer, 168-205. London: Longman.

7. Granger, S. \& Rayson, P. (1998) Automatic Profiling of Learner Texts. // Learner English on Computer. / Ed. by S. Granger. London and New York: Longman.

8. Sinclair, J. (2004) Trust the Text. London: Routledge.

9. Sinclair, J.M. (2004b) Trust the text. // Trust the text, 9-23. London: Routledge.

10. Wolter, B. (2006) Lexical Network Structures and L2 Vocabulary Acquisition: The Role of L1 Lexical/Conceptual Knowledge. // Applied Linguistics, 27(4), 741-747.

11. Wray, A. (2002) Formulaic Language and the Lexicon. Cambridge: CUP. 


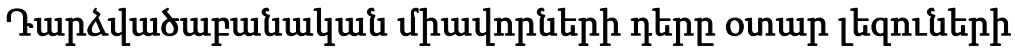 nuuuuluinuluis utis}

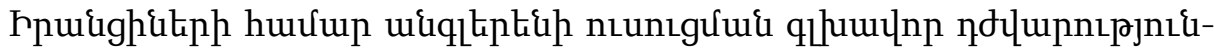

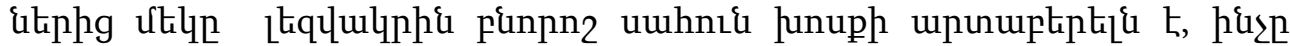

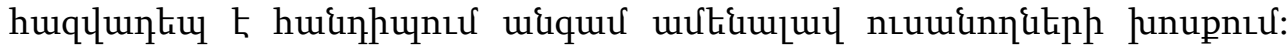

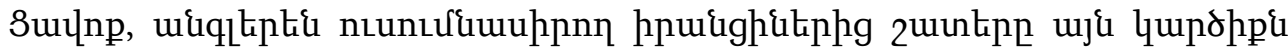

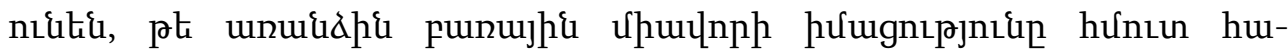

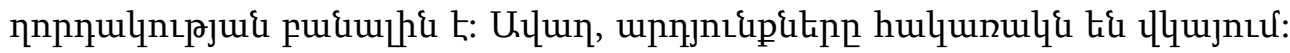

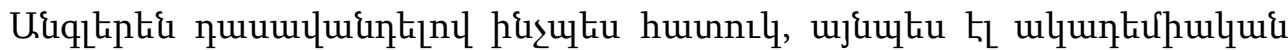

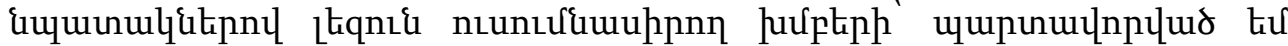

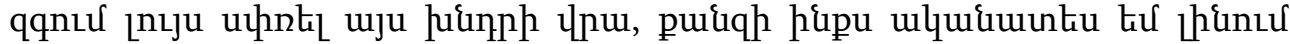

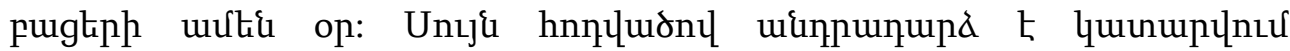

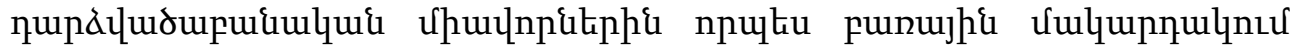

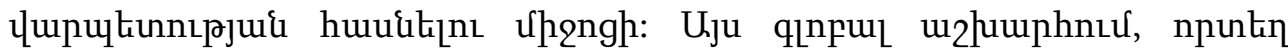

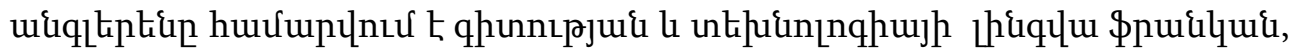

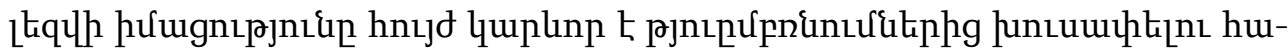

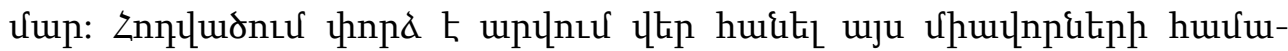

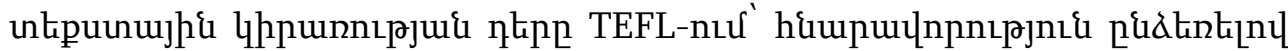

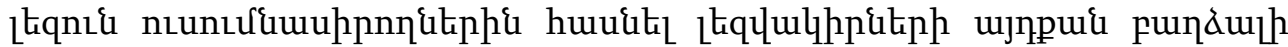
цupultinnıрjuin:

Received by Editorial Board 01.08.2019

Recommended for publication by Reviewers 22.09.2019

Accepted for Print 03.11.2019 